Administration Response to Heparin Contamination Helped Protect Public Health; Controls That Were Needed for Working with External Entities Were Recently Added (GAO; Washington, DC, 2010).

5. Olson, K. Alliance for Safe Biologic MedicinePrescriber Survey. http://safebiologics.org/resources/ wp-content/uploads/2012/09/ASBM-Survey-2.pdf (ISR, 2012; accessed 21 October 2013).

6. Vermeer, N. et al. Traceability of biologicals in adverse event reporting systems. Presented at 28th International Conference on Pharmacoepidemiology and Therapeutic Risk Management, Barcelona, Spain, 23-26 August 2012.

7. Booz Allen Hamilton. Evaluation of Potential Data Sources for the FDA Sentinel Initiative-Final Report. US Food and Drug Administration Contract No. HHSF223200831321P (Booz Allen Hamilton, Rockville, MD, 2010). http://www.regulations.gov/cont entStreamer?objectld=0900006480e6cd8d\&dispositio

$\mathrm{n}=$ attachment\&contentType $=$ pdf (accessed 17 January 2014)

8. US Food and Drug Administration. Part 15 Public Hearing on Approval Pathway for Biosimilar and Interchangeable Biological Products. (FDA, Silver Spring, MD, November 2, 2010). http://www.fda. gov/downloads/Drugs/NewsEvents/UCM289130.pdf (FDA, Silver Spring, MD, 2 November 2010; accessed 17 January 2014).

9. Getz, K. A Stergiopoulos, S. \& Kaitin, K.I. Am. J. Ther. 10.1097/MJT.0b013e318262316f (24 September 2012)

10. US Food and Drug Administration. Proprietary Name Review(s): BLA 125294 - [xxx]-Filgrastim (FDA, Center for Drug Evaluation and Research, Rockville, MD, 2012).

10. US Food and Drug Administration. Approval package for application number 1254180 rig1s000 (ziv-aflibercept) (FDA, Silver Spring, MD, 2012).

\title{
A divided INN crowd
}

\section{To the Editor:}

As Executive Vice President, Scientific and Regulatory Affairs at the Pharmaceutical Research and Manufacturers of America (PhRMA; Washington, DC), I was disturbed by your December editorial entitled 'The INN crowd' ${ }^{\text {'. Your editorial }}$ both misrepresents the current state of the pharmacovigilance system in the United States and proposes recommendations for the naming of biosimilars that pose a serious threat to patient safety.

Because biosimilars are similar to, but not the same as, their innovative biological reference products, patients, doctors, manufacturers and regulators must be able to distinguish between all biological medicines for the purposes of effective safety monitoring, data collection and transparency. PhRMA strongly believes that distinguishable nonproprietary names for all biological products, in conjunction with clear and informative labeling of biological products, are an essential component of a robust pharmacovigilance system that prioritizes patient safety.

The need for distinguishable names has been acknowledged by the World Health Organization (WHO; Geneva), which has a well-defined mandate through the WHO International Nonproprietary Names (INN) Programme to ensure clear identification, prescribing and dispensing of pharmaceutical substances, both chemically synthesized and biological products. In 2013, the WHO held a closed meeting entitled 'Discussion on INN Proposal for Similar Biological Products (SBPs)' during which, according to the public summary, "experts felt that the best way to do this [for biosimilar products] is through nomenclature with involvement of the INN Programme in developing a unique global qualifier." In fact, innovator companies have participated with other experts and regulatory authorities in an ongoing dialog on what policies would help the WHO to facilitate the appropriate identification of medicines, including at the recent 57th Open Consultation. In referencing the WHO's now-outdated 2006 position on naming, the editorial fails to acknowledge these more current multi-stakeholder discussions that recognize the clear need to improve the INN system for biological products.

Just as biosimilars are not the same as generic medicines (and should not be treated as such), INN policies for biosimilars should not follow the same naming conventions currently used for generics. To be clear, the editors misrepresented our position: PhRMA and the innovative biopharmaceutical industry have not advocated for entirely different INNs for each product. Indeed, we agree that such a practice would lead to confusion. Our position, which is to use a distinguishable identifier in addition to the core INN, builds upon current naming practices in a logical way. This would mean that nonproprietary names would be similar to each other in structure and function; be distinguishable, but morphologically related; and have the ability to be easily recognized, remembered and reported accurately by healthcare professionals and patients. Distinguishable but related nonproprietary names would also facilitate both the accurate attribution of safety signals at the product level and the aggregation of data to detect class-wide safety issues. With appropriate education, such a naming system would provide needed clarity and therefore greater confidence in prescribing of biosimilars.

The editorial pointed to the use of the National Drug Code (NDC) as a method for tracking adverse events in the United States but failed to acknowledge that the NDC is a 10 -digit numerical code that is prone to error and is not consistently included with adverse event reports. A recent study demonstrated that product name (brand or nonproprietary) is often the only meaningful product-specific information provided in the US Food and Drug Administration (FDA; Rockville, MD) Adverse Event Reporting System (FAERS) data ${ }^{2}$. Thus, when reporters submit adverse events identified only by shared nonproprietary names, the FDA may not be able to accurately identify the particular product associated with the report, therefore delaying or potentially making impossible the attribution of the adverse event to the correct product. Inability to accurately attribute adverse events to the correct product may undermine physician and patient confidence in all products in a class. Perhaps more importantly, it could also prevent the detection of rare safety signals from an individual company's product through dilution into an unidentified mass of adverse event reports.

With the introduction of biosimilars in the United States and the continued entry of new innovator biologic medicines into the market, treatment options for patients will expand over time. This fact makes the current policy discussion around how best to track and accurately attribute adverse drug reactions even more crucial. We have the opportunity to learn from past pharmacovigilance failures and work together toward developing a durable and robust pharmacovigilance system for all biological products. Trivializing the importance of distinguishable nonproprietary names as a means of reliably identifying products is irresponsible and potentially harmful for patients.

The recent editorial unfortunately misrepresented what should be a thoughtful, scientifically based policy debate and instead provided a false choice between patient access and patient safety. Patients deserve better.

\section{COMPETING FINANCIAL INTERESTS}

The author declares competing financial interests: details are available in the online version of the paper (doi:10.1038/nbt.2820)

\section{William W Chin}

PhRMA, Washington, DC, USA. e-mail:newsroom@phrma.org

1. Anonymous. Nat. Biotechnol. 31, 1055 (2013).

2. Lietzan, E. et al. Biosimilar naming: how do adverse event reporting data support the need for distinct nonproprietary names for biosimilars? Food and Drug Law Institute's Food and Drug Policy Forum (27 March 2013). 